Article

\title{
Acute Recanalization of Large Vessel Occlusion in the Anterior Circulation Stroke: Is Mechanical Thrombectomy Alone Better in Patients over 80 Years of Age? Findings from a Retrospective Observational Study
}

\author{
Dagmar Krajíčková $^{1}$, Antonín Krajina ${ }^{2}$, Roman Herzig ${ }^{1, * \mathbb{D}}$, Oldřich Vyšata ${ }^{1,3}$, Libor Šimůnek ${ }^{1}$ \\ and Martin Vališ 1
}

check for

updates

Citation: Krajíčková, D.; Krajina, A.; Herzig, R.; Vyšata, O.; Šimůnek, L.; Vališ, M. Acute Recanalization of Large Vessel Occlusion in the Anterior Circulation Stroke: Is Mechanical Thrombectomy Alone Better in Patients over 80 Years of Age? Findings from a Retrospective Observational Study. J. Clin. Med. 2021, 10, 4266. https://doi.org/ $10.3390 / \mathrm{jcm} 10184266$

Academic Editors: Hyo Suk Nam and Byung Moon Kim

Received: 31 May 2021

Accepted: 14 September 2021

Published: 20 September 2021

Publisher's Note: MDPI stays neutral with regard to jurisdictional claims in published maps and institutional affiliations.

Copyright: (c) 2021 by the authors. Licensee MDPI, Basel, Switzerland. This article is an open access article distributed under the terms and conditions of the Creative Commons Attribution (CC BY) license (https:/ / creativecommons.org/licenses/by/ $4.0 /)$.
1 Department of Neurology, Comprehensive Stroke Center, Charles University Faculty of Medicine and University Hospital, Sokolská 581, CZ-500 05 Hradec Králové, Czech Republic; dagmar.krajickova@fnhk.cz (D.K.); vysatao@gmail.com (O.V.); libor.simunek@email.cz (L.Š.); valismar@seznam.cz (M.V.)

2 Department of Radiology, Comprehensive Stroke Center, Charles University Faculty of Medicine and University Hospital, CZ-500 05 Hradec Králové, Czech Republic; antonin.krajina@fnhk.cz

3 Department of Computing and Control Engineering, University of Chemistry and Technology in Prague, Czech Republic, CZ-166 28 Prague 6, Czech Republic

* Correspondence: herzig.roman@seznam.cz

\begin{abstract}
Real-world data report worse 3-month clinical outcomes in elderly patients with acute ischemic stroke (AIS) treated with mechanical thrombectomy (MT). The aim was to identify factors influencing clinical outcome in elderly patients with anterior circulation AIS treated with MT ( \pm intravenous thrombolysis (IVT)). In a retrospective, monocentric study, analysis of prospectively collected data of 138 patients ( $\geq 80$ years) was performed. IVT was an independent negative predictor (OR 0.356; 95\% CI: 0.134-0.942) and female sex an independent positive predictor (OR 4.179, 95\% CI: 1.300-13.438) of 3-month good clinical outcome (modified Rankin scale 0-2). Female sex was also an independent negative predictor of 3-month mortality (OR 0.244, 95\% CI: 0.100-0.599). Other independent negative predictors of 3-month good clinical outcome were older age, lower pre-stroke self-sufficiency, more severe neurological deficit and longer procedural intervals. Mortality was also independently predicted by longer procedural interval and by the occurrence of symptomatic intracerebral hemorrhage ( $p<0.05$ in all cases). Our results demonstrated, that in patients aged $\geq 80$ years with anterior circulation AIS undergoing MT $( \pm$ IVT), IVT reduced the chance of 3-month good clinical outcome and female sex was associated with a greater likelihood of 3-month good clinical outcome and lower probability of 3-month mortality.
\end{abstract}

Keywords: anterior circulation; acute ischemic stroke; large vessel occlusion; elderly patients; mechanical thrombectomy; intravenous thrombolysis; bridging therapy; recanalization; clinical outcome

\section{Introduction}

Mechanical thrombectomy (MT) is currently the standard treatment for acute ischemic stroke (AIS) in the anterior circulation due to the emergent large vessel occlusion (ELVO). MT has been shown to lead to higher recanalization rates and better clinical outcomes in selected patients compared to intravenous thrombolysis (IVT) alone [1-5]. Although the guidelines recommend, unless there is a contraindication, treatment with intravenous recombinant tissue plasminogen activator (rtPA) before MT (bridging therapy) [6,7], there are doubts about the benefit of IVT preceding MT [8-16]. Real-world data consistently report worse 3-month clinical outcomes in elderly patients compared to younger patients [17-24]. Nevertheless, the factors influencing the clinical outcome in elderly patients have not been fully elucidated. 
The aim was to identify factors influencing the recanalization rate, the occurrence of symptomatic intracerebral hemorrhage $(\mathrm{sICH})$ and the clinical outcome in elderly patients ( $\geq 80$ years) with anterior circulation AIS due to ELVO undergoing MT ( \pm IVT) in routine clinical practice.

\section{Materials and Methods}

\subsection{Data Source and Study Population}

All relevant data used for this retrospective analysis were manually extracted from hospital information systems and available individual patient medical charts, including documentation from the referring hospital (in the case of patients with secondary transport), emergency physician notes, neurology notes, and medication administration records.

In a retrospective, monocentric study, a set of 138 consecutive elderly patients ( $\geq 80$ years) with anterior circulation AIS due to ELVO treated with MT using second generation stentretrievers ( \pm IVT) from January 2013 to June 2019 in the Comprehensive Stroke Center (CSC), University Hospital in Hradec Králové, Czech Republic, was analyzed. Some patients were transported to the CSC directly, others were transported to the CSC for MT from primary stroke centers (PSC). The indication for MT was determined in accordance with the valid guidelines [6,25-28].

\subsection{Computed Tomography Imaging}

Non-enhanced computed tomography (NECT) of the brain with the assessment of the Alberta Stroke Program Early CT Score (ASPECTS) and CT angiography (CTA) of the cervical and intracranial arteries including the evaluation of the collateral system was performed in all patients. For CTA, a non-ionic contrast iomeprol (Iomeron 400, Bracco, Torviscosa, Italy) was administered intravenously (total volume of $60 \mathrm{~mL}$, speed $4 \mathrm{~mL} / \mathrm{s}$ ). Patients treated more than $6 \mathrm{~h}$ from symptoms onset and patients with unknown AIS onset time also underwent perfusion CT (PCT) examination using $40 \mathrm{~mL}$ of the same contrast medium infused intravenously at $5 \mathrm{~mL} / \mathrm{s}$. The time to maximum (Tmax) delay $>6 \mathrm{~s}$ was used for the display of ischemic penumbra and, the relative cerebral blood flow $<30 \%$ of that in normal tissue for a diagnosis of ischemic core (irreversibly injured brain tissue) [29]. In patients with IVT administered in the PSC, a control brain NECT was performed in the CSC prior to MT initiation to exclude bleeding complications and the development of extensive cerebral infarction. A Somatom Definition AS + (Siemens, Forchheim, Germany) scanner was used for CT examinations.

\subsection{Intravenous Thrombolysis}

Intravenous thrombolysis with a standard dose of $0.9 \mathrm{mg} / \mathrm{kg}$ (maximum dose $90 \mathrm{mg}$ ) of recombinant tissue plasminogen activator (Actilyse, Boehringer Ingelheim, Ingelheim am Rhein, Germany) was applied in all patients with known stroke onset time fulfilling the inclusion and exclusion criteria according to the valid guidelines. Furthermore, $10 \%$ of the rtPA dose was administered as intravenous bolus, followed by a 60 -min infusion of the remaining $90 \%$ of the dose [30].

\subsection{Digital Subtraction Angiography and Mechanical Thrombectomy}

Within a 6-h time window from AIS symptoms onset, MT was performed in patients with ASPECTS $\geq 6$ on NECT. The result of PCT was crucial in patients treated more than $6 \mathrm{~h}$ from AIS symptoms onset and in patients with unknown AIS onset time-MT was performed in patients with a small ischemic core $(\leq 70 \mathrm{~mL}$; based of the results of previous studies [31]) and with the presence of ischemic penumbra. Patients without mismatch were excluded from therapy. A poor condition of the collateral system, if representing the only unfavorable prognostic factor, was not a reason for the exclusion from the MT. MT was started as soon as possible, not waiting for the IVT effect, if applied.

A biplane angio machine (Philips Allura FD 20/20, Best, The Netherlands) was used for DSA examination. Non-ionic contrast iodixanol (Visipaque 320, GE Healthcare AS, Oslo, 
Norway) was administered intra-arterially using a Seldinger technique (total volume of $6 \mathrm{~mL}$, speed $7 \mathrm{~mL} / \mathrm{s}$ ). For MT, second-generation stent-retrievers were used-Trevo (Trevo ProVue, Concentric Medical, Mountain View, CA, USA), Solitaire (Solitaire, Covidien, Dublin, Ireland), Eric 4 (ERIC 4 Retrieval Device, MicroVention Terumo, Saint-Germainen-Laye, France), and Preset (pREset, Phenox GmbH, Bochum, Germany). The choice of stent-retriever depended on the decision of the radiologist. In the majority of procedures, the balloon guiding catheter (Merci 8F, Concentric Medical, Mountain View, CA, USA) was placed within the internal carotid artery (ICA). In the presence of a loop, the catheter was placed below it. A microcatheter ( 0.021 inch) with stent-retriever was subsequently introduced. The stent-retriever was deployed across the occlusion and after 4 min the stent was slowly retrieved, while flow arrest in the accessing artery was applied by balloon inflation. Manual aspiration was applied through the guiding catheter via sidearm using a 20-cc syringe. In most cases, the procedure was performed under conscious sedation, without general anesthesia. Blood pressure was kept above $140 \mathrm{~mm} \mathrm{Hg}$.

\subsection{Observed Parameters}

The following data were collected: demographic data (age, sex, occurrence of vascular risk factors-arterial hypertension, diabetes mellitus, dyslipidemia, coronary artery disease, atrial fibrillation, prior stroke/transient ischemic attack), pre-intervention data (pre-stroke modified Rankin scale (mRS) value [32], direct/interhospital transfer, neurologic deficitassessed using the National Institutes of Health Stroke Scale (NIHSS) [33], initial ASPECTS values, presence of leukoaraiosis (defined as CT signs of hypodense lesions around the anterior and posterior horns of the lateral ventricles [34]), location of vessel occlusion), and procedural characteristics (time intervals-the time when the patient was last seen normal was used in patients with an unknown AIS onset time, number of stent-retriever passes (SRPs), recanalization rate assessed using TICI score with successful recanalization defined as TICI 2b/3 [35], occurrence of sICH defined according to the Safe Implementation of Thrombolysis in Stroke-Monitoring Study (SITS-MOST) criteria [36] and 3-month clinical outcome assessed using mRS-with good clinical outcome defined as 0-2 points). Clinical outcome was assessed by a certified treating neurologist not blinded for the result of the MT. In patients, who were unable to attend a follow-up visit at the CSC, a telephone interview with another treating physician or the family members was used.

\subsection{Statistical Analysis}

The normality of the distributions was confirmed using the Kolmogorov-Smirnov test. Fisher's exact test was used to assess the relationship between categorical variables. The Mann-Whitney U-test or unpaired $t$-test was used, depending on data normality, to evaluate the impact of quantitative parameters.

A multivariate linear logistic regression model was used for the prediction of successful recanalization, sICH occurrence, 3-month good clinical outcome, and 3-month mortality. Bonferroni test was used for multiple comparison. Multiple colinear time predictors have been reduced to "onset-to-groin puncture" and "groin puncture-to-end of intervention" independent predictors.

Standard multivariate logistic regression was separately used for each binary output variable of interest. In the initial model, 28 predictors were used. First, we examined possible hidden relationships between output variables and explanatory ones as they could cause difficulty to the estimation process on one hand, but on the other, could also provide direct implications between these two groups of variables.

Explanatory variables involved in such relationship with an output variable were excluded from the data set when estimating the corresponding model for this output variable. Then complete models were estimated using all input variables without hidden relationships with the dependent variable. As not all estimated coefficients in the complete models were significant at the level of 0.95 , we examined the justification of their inclusion into the model with the likelihood ratio (LR) test. Due to the large number of explanatory 
insignificant variables and their possible mutual dependency in many cases, the testing was proceeded as follows. First, we removed all statistically insignificant variables from the complete model and used the LR test to verify whether such exclusion was statistically justifiable. If not, we returned the previously eliminated variables into the model in a piecewise mode according their $p$ values in the full model until the null hypothesis of excluding the rest of them was not rejected by the LR test. For all explanatory variables included in final models we calculated their odds ratio and its corresponding confidence intervals.

The MATLAB Statistical Toolbox (MathWorks, Natick, MA, USA) was used for statistical analysis.

\subsection{Ethics}

The entire study was conducted in accordance with the Declaration of Helsinki of 1964 and its later amendments (including the last in 2013). All procedures were performed in accordance with institutional guidelines. The study was approved by the Ethics Committee of the University Hospital Hradec Králové (approval No. 201912 S16R). All conscious patients signed informed consent forms for the eligible and available diagnostics and treatment. Independent witnesses verified the signatures in cases in which there were technical problems.

\section{Results}

The set consisted of 138 elderly patients ( $\geq 80$ years) (98 females; mean age $84.6 \pm 3.5$ years), out of whom $57(41.3 \%)$ patients were treated with MT alone (MT-A) and $81(58.7 \%)$ patients with MT + IVT. Baseline characteristics are presented in Table 1.

Table 1. Baseline characteristics.

\begin{tabular}{|c|c|c|c|}
\hline Characteristic & MT-A $(n=57)$ & $\mathrm{IVT}+\mathrm{MT}(n=81)$ & $p$ \\
\hline Age, (years) ${ }^{+}$ & $84.6 \pm 3.7(83)(82-87)$ & $84.2 \pm 3.4(84)(81.75-87)$ & 0.51 \\
\hline Female sex & $43(75.4)$ & $55(67.9)$ & 0.79 \\
\hline \multicolumn{4}{|l|}{ Medical history } \\
\hline Arterial hypertension & $50(87.7)$ & $72(88.9)$ & 1.00 \\
\hline Diabetes mellitus & $19(33.3)$ & $25(30.9)$ & 0.86 \\
\hline Dyslipidemia & $21(36.8)$ & $30(37.0)$ & 1.00 \\
\hline Coronary artery disease & $22(38.6)$ & $27(33.3)$ & 0.74 \\
\hline Atrial fibrillation & $22(38.6)$ & $34(42.0)$ & 0.87 \\
\hline Prior stroke/TIA & $15(26.3)$ & $17(21.0)$ & 0.69 \\
\hline \multicolumn{4}{|l|}{ Pre-stroke mRS } \\
\hline $0-2$ & $32(56.1)$ & $56(69.1)$ & 0.49 \\
\hline $3-5$ & $15(26.3)$ & $13(16.0)$ & 0.30 \\
\hline Uncertain & $10(17.5)$ & $12(14.8)$ & 0.82 \\
\hline Unknown symptom onset & $22(38.6)$ & $13(16.0)$ & 0.04 \\
\hline Direct transfer to the CSC & $45(78.9)$ & $55(67.9)$ & 0.18 \\
\hline Initial qualifying NIHSS ${ }^{\dagger}$ & $14.9 \pm 4.6(15)(12-18)$ & $15.0 \pm 4.9(15)(13-17)$ & 0.87 \\
\hline \multicolumn{4}{|l|}{ Initial CT characteristics } \\
\hline ASPECTS-all patients ${ }^{\dagger}$ & $8.7 \pm 1.0(9)(8-9)$ & $8.1 \pm 1.4(8)(7-9)$ & 0.002 \\
\hline ASPECTS - direct transfer to the $\mathrm{CSC}^{\dagger}$ & $8.8 \pm 1.1(9)(9-10)$ & $8.1 \pm 1.4(8)(7-9)$ & 0.008 \\
\hline ASPECTS—interhospital transfer ${ }^{\dagger}$ & $8.4 \pm 0.8(9)(8-9)$ & $7.9 \pm 1.3(8)(7-9)$ & 0.24 \\
\hline Leukoaraiosis & $21(36.8)$ & $33(40.7)$ & 0.87 \\
\hline \multicolumn{4}{|l|}{ Occluded vessel } \\
\hline M1 & $35(61.4)$ & $47(58.0)$ & 0.89 \\
\hline M2 & $10(17.5)$ & $11(13.6)$ & 0.64 \\
\hline Distal ICA + M1 (L occlusion) & $9(15.8)$ & $11(13.6)$ & 0.63 \\
\hline Distal ICA + M1 + A1 (T occlusion) & $1(1.8)$ & $4(4.9)$ & 0.65 \\
\hline ICA + M1 (tandem occlusion) & $2(3.5)$ & $8(9.9)$ & 0.09 \\
\hline IVT & $0(0)$ & $81(100.0)$ & \\
\hline $\mathrm{IVT} \leq 3 \mathrm{~h}$ & $0(0)$ & $75(92.6)$ & \\
\hline
\end{tabular}

Data are $n(\%)$ for categorical variables or mean \pm SD (median) (IQR) for numerical variables ${ }^{\dagger}$. ASPECTS, Alberta Stroke Program Early CT Score; CSC, Comprehensive Stroke Center; CT, computed tomography; ICA, internal carotid artery; IQR, interquartile range; IVT, intravenous thrombolysis; M1, middle cerebral artery—segment 1; M2, middle cerebral artery—segment 2; mRS, modified Rankin scale; MT, mechanical thrombectomy; MT-A, MT alone; $n$, number of patients; NIHSS, National Institutes of Health Stroke Scale; SD, standard deviation; TIA, transient ischemic attack. 
In patients treated with MT-A versus MT + IVT, there was significantly more frequent unknown symptom onset ( $38.6 \%$ versus $16.0 \%, p=0.04)$ and ASPECTS values were significantly higher-both in the whole sets (mean 8.7 versus $8.1, p=0.002$ ) and in the subgroups of patients with direct transfer to the CSC ( 8.8 versus $8.1, p=0.008$ ).

As the first stent-retriever, Trevo was used 104 times (75.4\%), Solitaire 32 times (23.2\%), and both Eric 4 and Preset were used once. Two types of stent-retrievers were used twice during one procedure. One SRP was sufficient in $49.3 \%$ of patients, more than three SRPs were needed in $10.1 \%$ of patients. Furthermore, 26 out of 38 patients with secondary transport to the CSC were treated with IVT in the PSC. This represents only $32.1 \%$ out of 81 patients treated with IVT and this small proportion does not allow evaluation of the benefit and risk of this treatment prior to patients' transfer to the CSC. As presented in Table 2, IVT administration did not delay the start of MT, the interval from the known time of onset-togroin puncture was even slightly shorter in the IVT + MT group than in the MT-A group. Door intervention center-to-groin puncture time was shorter by about half in patients with secondary transport to the CSC than in patients with direct transfer, because the emergency department and intervention team were pre-activated by the PSC. In the whole group, sICH occurred in $6.5 \%$ of patients-more frequently in patients with unknown time of symptoms onset $(8.6 \%)$, with interhospital transfer $(7.9 \%)$, with leukoaraiosis $(11.1 \%)$, and with IVT $(8.6 \%)$. The same factors reduced the chances of the achievement of a good clinical outcome (30.4\% in the whole group) and increased the mortality $(36.2 \%$ in the whole group) $-28.6 \%$ and $40.0 \%$ in patients with unknown time of symptoms onset, $26.3 \%$ and $42.1 \%$ with interhospital transfer, $22.2 \%$ and $42.6 \%$ with leukoaraiosis and, $25.9 \%$ and $40.7 \%$ with IVT. By day 10 , only $26 \%$ of patients had died, with the largest number $(40 \%)$ dying between days 31 and 90 . Pre-stroke mRS affected both the achievement of good clinical outcome $(45.5 \%$ in patients with pre-stroke mRS $\leq 2)$ and mortality $(29.5 \%$ in patients with pre-stroke $m R S \leq 2$ and $46.4 \%$ with pre-stroke $\mathrm{mRS} 3-5$ ). Procedural characteristics and outcomes in particular groups are presented in Table 2.

Table 2. Procedural characteristics and outcomes.

\begin{tabular}{|c|c|c|c|c|}
\hline \multicolumn{2}{|c|}{ Characteristic } & MT-A $(n=57)$ & IVT + MT $(n=81)$ & $p$ \\
\hline \multirow{7}{*}{ Time intervals (min) } & Onset-to-needle $^{\dagger}$ & & $117.7 \pm 38.6(120.0)(98.5-140.0)$ & \\
\hline & Onset-to-groin puncture $^{+}$ & $209.0 \pm 93.4(184.0)(141-265)$ & $197.0 \pm 63.3(178.5)(145-229.5)$ & 0.42 \\
\hline & $\begin{array}{c}\text { Door intervention } \\
\text { center-to-groin puncture }\end{array}$ & $78.6 \pm 32.9(79.5)(56-106)$ & $72.8 \pm 27.8$ (74) (51.75-91.25) & 0.31 \\
\hline & Direct transfer to the $\mathrm{CSC}^{+}$ & $89.5 \pm 27.7$ (85.5) (70.5-105) & $85.5 \pm 22.0(83.0)(72.5-101)$ & 0.42 \\
\hline & Interhospital transfer ${ }^{\dagger}$ & $40.8 \pm 22.2(30.0)(27-50.5)$ & $47.5 \pm 19.2(40.5)(32.5-56)$ & 0.35 \\
\hline & $\begin{array}{l}\text { Groin puncture-to-end } \\
\text { of intervention }\end{array}$ & $46.8 \pm 27.2(40.0)(28-58)$ & $46.2 \pm 27.3(38.5)(25-56)$ & 0.91 \\
\hline & Onset-to-end of intervention ${ }^{\dagger}$ & $257.7 \pm 98.2(255)(173-313)$ & $242.8 \pm 67.3(228.5)(191.5-286)$ & 0.37 \\
\hline \multirow{4}{*}{$\begin{array}{l}\text { Stent-retriever } \\
\text { passes }\end{array}$} & All patients ${ }^{\dagger}$ & $2.1 \pm 1.6(2)(1-3)$ & $1.9 \pm 1.0(2)(1-3)$ & \\
\hline & 1 & $27(47.4)$ & $41(50.6)$ & 0.88 \\
\hline & 2 & $14(24.6)$ & $19(23.5)$ & 1.00 \\
\hline & $\geq 3$ & $7(12.3)$ & $7(8.7)$ & 0.58 \\
\hline \multirow{6}{*}{$\begin{array}{l}\text { Recanalization } \\
\text { grade }\end{array}$} & TICI 0 & $6(10.5)$ & $2(2.5)$ & 0.08 \\
\hline & TICI 1 & $0(0)$ & $2(2.5)$ & 0.51 \\
\hline & TICI 2a & $9(15.8)$ & $14(17.3)$ & 1.00 \\
\hline & TICI $2 b$ & $14(24.6)$ & $25(30.9)$ & 0.58 \\
\hline & TICI 3 & $28(49.1)$ & $38(46.9)$ & 0.88 \\
\hline & $\mathrm{TICI} \geq 2 \mathrm{~b}$ & $42(73.7)$ & $63(77.8)$ & 0.90 \\
\hline
\end{tabular}


Table 2. Cont.

\begin{tabular}{|c|c|c|c|c|}
\hline \multicolumn{2}{|c|}{ Characteristic } & \multirow{2}{*}{$\begin{array}{c}\text { MT-A }(n=57) \\
2(3.5)\end{array}$} & \multirow{2}{*}{$\begin{array}{c}\text { IVT + MT }(n=81) \\
7(8.6)\end{array}$} & \multirow{2}{*}{$\begin{array}{c}p \\
0.32\end{array}$} \\
\hline \multirow{7}{*}{$\begin{array}{c}\text { sICH } \\
\text { occurrence }\end{array}$} & All patients & & & \\
\hline & Pre-stroke $\mathrm{mRS} \leq 2$ & $1 / 32(3.1)$ & $5 / 56(8.9)$ & 0.41 \\
\hline & Unknown symptom onset & $1 / 22(4.5)$ & 2/13 (15.4) & 0.55 \\
\hline & Direct transfer to the CSC & $2 / 45(4.4)$ & $4 / 55(7.3)$ & 0.69 \\
\hline & Interhospital transfer & $0(0)$ & $3 / 26(11.5)$ & \\
\hline & Leukoaraiosis & $1 / 21(4.8)$ & $5 / 33(15.2)$ & 0.40 \\
\hline & IVT & & $7(8.6)$ & \\
\hline \multirow{7}{*}{$\begin{array}{l}\text { 3-month good } \\
\text { clinical } \\
\text { outcome } \\
\text { (mRS 0-2) }\end{array}$} & All patients & $21(36.8)$ & $21(25.9)$ & 0.38 \\
\hline & Pre-stroke $\mathrm{mRS} \leq 2$ & $21 / 32(65.7)$ & $19 / 56(33.9)$ & 0.12 \\
\hline & Unknown symptom onset & $8 / 22(36.4)$ & $2 / 13(15.4)$ & 0.46 \\
\hline & Direct transfer to the CSC & $17 / 45(37.8)$ & $15 / 55(27.3)$ & 0.54 \\
\hline & Interhospital transfer & $4 / 12(33.3)$ & $6 / 26(23.1)$ & 0.71 \\
\hline & Leukoaraiosis & $5 / 21(23.8)$ & $7 / 33(21.2)$ & 1.00 \\
\hline & IVT & & $21(25.9)$ & \\
\hline \multirow{10}{*}{$\begin{array}{l}\text { 3-month } \\
\text { mortality } \\
(\mathrm{mRS} 6)\end{array}$} & All patients & $17(29.8)$ & $33(40.7)$ & 0.21 \\
\hline & Day $1-10$ & 5/17 (29.4) & $8 / 33(24.2)$ & 0.76 \\
\hline & Day $11-30$ & $6 / 17(35.3)$ & $11 / 33(33.3)$ & 1.00 \\
\hline & Day 31-90 & $6 / 17(35.3)$ & $14 / 33(42.4)$ & 1.00 \\
\hline & Pre-stroke $m R S \leq 2$ & $7(21.9)$ & $19(33.9)$ & 0.48 \\
\hline & Unknown symptom onset & $8 / 22(36.4)$ & $6 / 13(46.2)$ & 0.75 \\
\hline & Direct transfer to the CSC & $12 / 45(26.7)$ & $22 / 55(40.0)$ & 0.42 \\
\hline & Interhospital transfer & $5 / 12(41.7)$ & $11 / 26(42.3)$ & 1.00 \\
\hline & Leukoaraiosis & $8 / 21(38.1)$ & $15 / 33(45.5)$ & 0.80 \\
\hline & IVT & & $33(40.7)$ & \\
\hline
\end{tabular}

Data are $n(\%)$ for categorical variables or mean $\pm \mathrm{SD}$ (median) (IQR) for numerical variables ${ }^{\dagger} . \mathrm{CSC}$, Comprehensive Stroke Center; IQR, interquartile range; IVT, intravenous thrombolysis; $\mathrm{mRS}$, modified Rankin scale; MT, mechanical thrombectomy; MT-A, MT alone; $n$, number of patients; SD, standard deviation; sICH, symptomatic intracerebral hemorrhage; TICI, Thrombolysis in Cerebral Infarction.

As presented in Table 3, higher number of stent-retriever passes was identified as an independent negative predictor of the achievement of successful recanalization. Higher ASPECTS value was identified as an independent negative predictor and the presence of leukoaraiosis as an independent positive predictor of the sICH occurrence. IVT was identified as an independent negative predictor of the achievement of 3-month good clinical outcome. Female sex was identified as an independent positive predictor of the achievement of 3-month good clinical outcome and as an independent negative predictor of 3-month mortality. Other independent negative predictors of the achievement of 3-month good clinical outcome were, as expected, older age, lower pre-stroke self-sufficiency, more severe neurological deficit and longer time intervals (onset-to-groin, groin puncture-to-end of intervention). In addition to older age, mortality was independently predicted by the longer groin puncture-to-end of intervention interval and by the sICH occurrence (Table 3).

Table 3. Significant independent predictors of the observed parameters—results of multivariate logistic regression analysis.

\begin{tabular}{|c|c|c|c|}
\hline Observed Parameter & Predictor & OR $(95 \%$ CI $)$ & $p$ \\
\hline $\begin{array}{l}\text { Successful } \\
\text { recanalization } \\
(\mathrm{TICI} 2 \mathrm{~b} / 3)\end{array}$ & Number of stent-retriever passes & $0.537(0.376-0.766)$ & $6 \times 10^{-4}$ \\
\hline $\mathrm{sICH}$ & $\begin{array}{c}\text { ASPECTS } \\
\text { Leukoaraiosis }\end{array}$ & $\begin{array}{c}0.559(0.320-0.977) \\
4.947(1.036-23.619)\end{array}$ & $\begin{array}{l}0.041 \\
0.045\end{array}$ \\
\hline 3-month good clinical outcome (mRS 0-2) & $\begin{array}{c}\text { Age } \\
\text { Female sex } \\
\text { Pre-stroke mRS } \\
\text { NIHSS value } \\
\text { IVT } \\
\text { Onset-to-groin interval } \\
\text { Groin puncture-to-end of } \\
\text { intervention }\end{array}$ & $\begin{array}{c}0.803(0.689-0.937) \\
4.179(1.300-13.438) \\
0.052(0.006-0.477) \\
0.856(0.756-0.968) \\
0.356(0.134-0.942) \\
0.991(0.984-0.999) \\
0.964(0.941-0.987)\end{array}$ & $\begin{array}{l}0.005 \\
0.016 \\
0.009 \\
0.013 \\
0.038 \\
0.023 \\
0.002\end{array}$ \\
\hline
\end{tabular}


Table 3. Cont.

\begin{tabular}{|c|c|c|c|}
\hline Observed Parameter & Predictor & OR $(95 \% \mathrm{CI})$ & $p$ \\
\hline \multirow{4}{*}{$\begin{array}{l}\text { 3-month mortality } \\
\text { (mRS 6) }\end{array}$} & Age & $1.250(1.106-1.413)$ & $3 \times 10^{-4}$ \\
\hline & Female sex & $0.244(0.100-0.599)$ & 0.002 \\
\hline & $\begin{array}{l}\text { Groin puncture-to-end of } \\
\text { intervention }\end{array}$ & 1.015 (1.001-1.030) & 0.040 \\
\hline & $\mathrm{sICH}$ & $6.681(1.171-38.105)$ & 0.032 \\
\hline
\end{tabular}

ASPECTS, Alberta Stroke Program Early CT Score; CI, confidence interval; IVT, intravenous thrombolysis; mRS, modified Rankin scale; NIHSS, National Institutes of Health Stroke Scale; OR, odds ratio; sICH, symptomatic intracerebral hemorrhage; TICI, Thrombolysis in Cerebral Infarction.

\section{Discussion}

About $30 \%$ of patients with AIS are aged 80 and over, $17 \%$ are even older than 85 years, and the proportion of elderly patients will continue to increase as the population ages [37,38]. The fact that AIS due to ELVO in elderly patients has a poor prognosis without MT (in the medical arm/IVT group of HERMES meta-analysis only $13.9 \%$ of these patients achieved mRS $0-2$ and their mortality was $45.2 \%$ [18]) supports the legitimacy of the use of MT in this age group, although its results are significantly worse compared to younger patients despite similar successful recanalization rates [17-24]. In the HERMES meta-analysis, in patients treated with MT, mRS $\leq 2$ was achieved in $46 \%$ of patients aged $57-77$ years and only in $29.8 \%$ of patients aged $\geq 80$ years, and, mortality was $15.3 \%$ and $28 \%$ in particular groups $[1,3,5]$. In the STRATIS registry of patients treated with MT, rates of good clinical outcomes significantly decreased for each 5 -year increment of age from $<65$ to $>90$ years, from $64.3 \%$ to $26.5 \%$, while mortality significantly increased from $7.9 \%$ to $35.1 \%$ [19]. In the TREVO registry, $33.7 \%$ of patients aged $\geq 80$ years reached $m R S \leq 2$ and their mortality was $27.2 \%$, while the same values for younger patients were 62.2 and $9.6 \%$, respectively [20]. Out of 560 patients treated with MT in seven US centers, 108 patients aged $\geq 80$ years also had significantly worse clinical outcomes when compared with younger patientsmRS $\leq 2$ was achieved in $20.5 \%$ versus $44.4 \%$ and mortality was $34.3 \%$ versus $20 \%$ in particular groups [21]. Our results are comparable to those published-3-month good clinical outcome (mRS $\leq 2)$ was achieved in $30.4 \%$ of our patients aged $\geq 80$ years and their 3-month mortality was $36.2 \%$.

Older patients have poor clinical outcome at 3 months despite high rates of the achieved recanalization. In our group, successful recanalization (TICI $2 b / 3$ ) was achieved in $76.1 \%$ of patients aged $\geq 80$ years. In the work published in 2016, early neurological improvement depended on successful recanalization, not on the age of MT-treated patients. However, older patients exhibited poor mid-term functional outcome due to post-stroke complications and other factors that were not, or only indirectly, related to the brain tissue damage induced by the incident stroke [39]. Corresponding to our finding is that a larger proportion of patients aged $\geq 80$ years died later- $40 \%$ of them between days 31 and 90 , when a direct association with brain tissue damage due to stroke is unlikely. Factors that adversely affect the prognosis in older patients may be pre-existing neuronal loss and reduced neuronal plasticity, leukoaraiosis, higher rate of comorbidities, and poststroke complications (e.g., infections or injuries due to falls) [40,41]. In our patients with leukoaraiosis, when compared to the whole group, we recorded a higher occurrence of sICHs $(11.1 \%$ versus $6.5 \%)$ and higher 3 -month mortality $(42.6 \%$ versus $36.2 \%)$ and a less frequent 3 -month good clinical outcome (22.2\% versus $30.4 \%)$. Due to pre-existing changes, the brain of elderly patients has depleted or borderline functional capacity, and is therefore able to tolerate only a small volume of infarction [42,43].

Whether treatment with IVT before MT in patients with anterior circulation stroke due to ELVO is of any benefit is currently one of the most important unanswered questions in acute stroke management [16]. To date, the results of randomized control trials (RCTs), as well as several registries and multicenter and single-center studies, suggest that MT-A is equally effective and not inferior to MT + IVT, if patients are immediately treated in stroke centers with rapid access to endovascular procedures. This was recently confirmed 
by multicenter RCTs from China and Japan (DIRECT-MT [44], DEVT [45], and SKIP [46]), which did not show a statistically significant difference between patients treated with MT-A versus MT + IVT in self-sufficiency at 3 months $(36.4 \%, 54.3 \%$, and $59.4 \%$ versus $36.8 \%, 46.6 \%$, and $57.3 \%$, resp.) or in mortality $(17.7 \%, 17.2 \%$, and $7.9 \%$ versus $18.8 \%, 17.8 \%$, and $8.7 \%$, resp.). In the DIRECT-MT trial, even a $5 \%$ higher successful recanalization rate achieved in patients treated with MT + IVT did not lead to a better functional outcome, and a relatively lower achievement of independence in both treatment groups was probably due to remarkably low rates of favorable collaterals [44]. Meta-analysis of six older RCTs with 940 patients treated with IVT and endovascular treatment and 107 patients treated with endovascular treatment alone showed that endovascular treatment was associated with a higher likelihood of the achievement of better outcome at 3 months-both in the group with IVT (OR 1.83) and without IVT (OR 2.47) [10]. The results of the meta-analysis of eight RCTs were similar [13]. No statistically significant differences were also confirmed by the pooled analysis of SWIFT and STAR studies [11]. Similar clinical outcomes at 90 days (either good clinical outcome, mortality, or both) in patients treated with MT-A and MT + IVT were also found in the Catalan SONIIA registry from 2011 to 2015 [12], Bernese Stroke Registry (with the exception of a lower mortality in the MT-A group) [9] (even after adding patients from the Essen registry, despite the fact that MT was delayed by $1 \mathrm{~h}$ in patients with MT + IVT [14]), and in other studies [8,15]. However, there are also works reporting better outcomes in patients treated with MT + IVT than with MT-A. In the German REVASK registry from 2012 to 2013, comparing patients with MT + IVT and MT-A, good 3-month clinical outcome was achieved in $47.5 \%$ versus $38.1 \%$ and mortality was $17.8 \%$ versus $27.8 \%$ in particular groups. As well as in our patient set, patients with MT + IVT had shorter times to groin puncture [47]. IVT was a predictor of the achievement of good outcome in another German registry from 2015 to 2018 (OR 1.49) [23], and better functional outcome (adjusted OR (aOR) 1.47 and 1.4, resp.) and lower mortality (aOR 0.58 and 0.74 , resp.) were found in patients treated with IVT + MT versus MT-A in the Dutch MR CLEAN registry from 2014 to 2016 [48] and in the international SITS-ISTR registry from 2014 to 2016 [49]. Data regarding the effect of IVT preceding MT on ICH frequency vary. In the SONIIA registry [12], MR CLEAN registry [48], and SITS-ISTR registry [49], the occurrence of sICH in both treatment groups was similar- $3.4 \%, 5.9 \%$, and $3.5 \%$, respectively, in the IVT + MT group versus $2.7 \%, 5.3 \%$, and $3.0 \%$, respectively, in the MT-A group. On the other hand, the German registries showed a significantly higher incidence of sICH in patients with MT + IVT $(4.5 \%, 5.3 \%$, and $3.5 \%$, resp.) versus patients with MT-A $(2.5 \%, 2.7 \%$, and $1.6 \%$, resp. $)[9,14,47]$ and also of ICH according to the ECASS II definition [50] irrespective of the new clinical symptoms (15\% versus $11 \%$ in particular groups) [23]. In the Bernese Stroke Registry, lower rate of asymptomatic ICH was observed in the MT-A versus MT + IVT group (12.5\% versus $20 \%$ ) [9]. Some authors [51,52] state that extensive leukoaraiosis may increase the risk of sICH in addition to IVT, and our results correspond with this.

We found the evaluation of the effect of IVT adjusted for age only in the study from Australia from 2016 to 2018 performed by Sharobeam et al. [22]. In older ( $\geq 80$ years) versus younger patients, treated for anterior circulation stroke with MT using second generation stent-retrievers, IVT was used in 34\% versus $45 \%$, procedure duration was 35 versus $31 \mathrm{~min}$, the occurrence of sICH according to the SITS-MOST definition was $4 \%$ versus $5 \%$, mRS $0-2$ at 90 days was achieved in $28 \%$ versus $55 \%$, and mortality rate was $27 \%$ versus $16 \%$ in particular groups. IVT was significantly associated with a favorable outcome in younger patients (OR 2.90), but not in elderly patients. In our study, IVT was identified as an independent negative predictor of the achievement of 3-month good clinical outcome (OR 0.356).

Females, representing $71 \%$ of our patients, achieved a better outcome-female sex was identified as an independent positive predictor of the achievement of 3-month good clinical outcome (OR 4.179) and as an independent negative predictor of 3-month mortality (OR 0.244). The conclusions of recent studies that reported sex differences in clinical outcome after MT are inconsistent. Studies analyzing large groups of younger patients 
(median age of females 69-70 years) from RCTs conclude that despite the fact that females were older and had a higher comorbidity compared to males, their clinical outcome after MT was comparable and according to the study performed by Sheth et al., females had significantly more years of optimal life (disability-adjusted life year) when compared to males (10.6 versus 8.5 years) [53,54]. In contrast, in the Japanese RESCUE registry, females (mean age 79.7 years), when compared to males (mean age 72.8 years), were less likely to achieve a good clinical outcome ( $27.3 \%$ versus $44.2 \%$; aOR 0.80$)$ and had higher mortality (12.3\% versus $9.9 \%$; aOR 0.78$)$ [55]. The most similar to our cohort is the cohort of 279 patients treated with MT in a single, large, academic CSC in the USA between 2015 and 2017. Females, representing $52 \%$ of patients, were older than males (median age 81 versus 71.5 years). Although at discharge both males and females had a similar probability of functional independence (aOR 0.71), at 90 days the probability of functional independence was apparently lower in females (aOR 0.37). Post hoc multivariate logistic regression analysis in subgroups by age indicated a greater sex difference for independence in females under 75 years (OR 0.24), while OR for females older than 75 years compared to males was 0.54 . However, the authors point out that the results of the subanalysis may not be reliable and are likely underpowered. The fact that both rates of successful recanalization and clinical outcome at discharge were similar between females and males, suggests that a worse long-term clinical outcome may reflect a less favorable situation of females not directly related to MT, such as their more frequent social isolation or lower social level. Females in this group were less likely to be married $(38.2 \%$ versus $67.5 \%)$ and were more likely to have government-sponsored insurance $(86.8 \%$ versus $73.1 \%)$ when compared to males [56]. The absence of greater social disparities and the general availability of outpatient or inpatient social services for the elderly in our country may have contributed to better long-term clinical outcomes after MT in females in our cohort, but do not explain the difference in outcome between the sexes.

Other independent negative predictors of the achievement of 3-month good clinical outcome were, as expected, older age, lower pre-stroke self-sufficiency, more severe neurological deficit, and longer time intervals (onset-to-groin, groin puncture-to-end of intervention). In addition to older age, mortality was independently predicted by the longer groin puncture-to-end of intervention interval and by the sICH occurrence.

Several limitations of the present study should be mentioned. First, it has a retrospective character with a sample extracted from a single stroke center database; therefore, the results may not be generalizable. Second, the data collection methods among databases may be the source of selection bias. Third, a relatively small number of patients in particular treatment subgroups limits the power for comparative analysis.

\section{Conclusions}

Our results demonstrated, that in patients with anterior circulation AIS due to ELVO aged $\geq 80$ years and undergoing MT $( \pm$ IVT), IVT reduced the chance of the achievement of 3-month good clinical outcome and female sex was associated with a greater likelihood of the achievement of 3-month good clinical outcome and lower probability of 3-month mortality. However, these results require verification on a larger set of patients.

Author Contributions: Conceptualization, D.K. and R.H.; data curation, D.K., A.K. and L.Š.; formal analysis, R.H. and O.V.; funding acquisition, M.V.; investigation, D.K., A.K. and L.Š.; methodology, D.K. and R.H.; project administration, D.K., R.H. and L.Š.; resources, D.K., A.K., R.H. and L.Š; software, O.V.; supervision, R.H.; validation, R.H.; writing-original draft, D.K., R.H. and O.V.; writing-review and editing, D.K., A.K., R.H., O.V., L.Š. and M.V. All authors have read and agreed to the published version of the manuscript.

Funding: This work was supported in part by the Ministry of Health of the Czech Republic (grant number DRO-UHHK 00179906) and Charles University, Czech Republic (grant number PROGRES Q40). 
Institutional Review Board Statement: The study was conducted according to the guidelines of the Declaration of Helsinki, and approved by the Ethics Committee of the University Hospital Hradec Králové, Czech Republic (approval No. 201912 S16R) on 5 December 2019.

Informed Consent Statement: Given the retrospective nature of the study, the individual consent to participate was not required after the approval from the local Ethics Committee.

Data Availability Statement: The datasets analyzed during the current study are available from the corresponding author on reasonable request.

Conflicts of Interest: The authors declare no conflict of interest. The funders had no role in the design of the study; in the collection, analyses, or interpretation of data; in the writing of the manuscript, or in the decision to publish the results.

\section{References}

1. Berkhemer, O.A.; Fransen, P.S.S.; Beumer, D.; Van den Berg, L.A.; Lingsma, H.F.; Yoo, A.J.; Schonewille, W.J.; Vos, J.A.; Nederkoorn, P.J.; Wermer, M.J.H.; et al. A randomized trial of intraarterial treatment for acute ischemic stroke. N. Engl. J. Med. 2015, 372, 11-20. [CrossRef]

2. Campbell, B.C.; Mitchell, P.J.; Kleinig, T.; Dewey, H.M.; Churilov, L.; Yassi, N.; Yan, B.; Dowling, R.J.; Parsons, M.W.; Oxley, T.J.; et al. Endovascular therapy for ischemic stroke with perfusion-imaging selection. N. Engl. J. Med. 2015, 372, 1009-1018. [CrossRef]

3. Goyal, M.; Demchuk, A.M.; Menon, B.K.; Eesa, M.; Rempel, J.L.; Thornton, J.; Roy, D.; Jovin, T.G.; Willinsky, R.A.; Sapkota, B.L.; et al. Randomized assessment of rapid endovascular treatment of ischemic stroke. N. Engl. J. Med. 2015, 372, 1019-1030. [CrossRef] [PubMed]

4. $\quad$ Saver, J.L.; Goyal, M.; Bonafe, A.; Diener, H.-C.; Levy, E.I.; Pereira, V.M.; Albers, G.W.; Cognard, C.; Cohen, D.J.; Hacke, W.; et al. Stent-retriever thrombectomy after intravenous t-PA vs. t-PA alone in stroke. N. Engl. J. Med. 2015, 372, 2285-2295. [CrossRef] [PubMed]

5. Jovin, T.G.; Chamorro, A.; Cobo, E.; De Miquel, M.A.; Molina, C.A.; Rovira, A.; Román, L.S.; Serena, J.; Abilleira, S.; Ribo, M.; et al. Thrombectomy within $8 \mathrm{~h}$ after symptom onset in ischemic stroke. N. Engl. J. Med. 2015, 372, 2296-2306. [CrossRef] [PubMed]

6. $\quad$ Powers, W.J.; Rabinstein, A.A.; Ackerson, T.; Adeoye, O.M.; Bambakidis, N.C.; Becker, K.; Biller, J.; Brown, M.; Demaerschalk, B.M.; Hoh, B.; et al. Guidelines for the early management of patients with acute ischemic stroke: A guideline for healthcare professionals from the American Heart Association/American Stroke Association. Stroke 2018, 49, e46-e110. [CrossRef]

7. Šaňák, D.; Mikulík, R.; Tomek, A.; Bar, M.; Herzig, R.; Neumann, J.; Škoda, O.; Školoudík, D.; Václavík, D.; Roček, M.; et al. Doporučení pro mechanickou trombektomii akutního mozkového infarktu-Verze 2019. Cesk. Slov. Neurol. N. 2019, 82/115, 700-705. [CrossRef]

8. $\quad$ Leker, R.R.; Pikis, S.; Gomori, J.M.; Cohen, J.E. Is bridging necessary? A pilot study of bridging versus primary stentretriever-based endovascular reperfusion in large anterior circulation strokes. J. Stroke Cerebrovasc. Dis. 2015, 24, 1163-1167. [CrossRef]

9. Broeg-Morvay, A.; Mordasini, P.; Bernasconi, C.; Bühlmann, M.; Pult, F.; Arnold, M.; Schroth, G.; Jung, S.; Mattle, H.P.; Gralla, J.; et al. Direct mechanical intervention versus combined intravenous and mechanical intervention in large anterior circulation stroke: A matched-pairs analysis. Stroke 2016, 47, 1037-1044. [CrossRef]

10. Tsivgoulis, G.; Katsanos, A.H.; Mavridis, D.; Magoufis, G.; Arthur, A.; Alexandrov, A.V. Mechanical thrombectomy improves functional outcomes independent of pretreatment with intravenous thrombolysis. Stroke 2016, 47, 1661-1664. [CrossRef]

11. Coutinho, J.M.; Liebeskind, D.S.; Slater, L.A.; Nogueira, R.G.; Clark, W.; Dávalos, A.; Bonafé, A.; Jahan, R.; Fischer, U.; Gralla, J.; et al. Combined intravenous thrombolysis and thrombectomy vs. thrombectomy alone for acute ischemic stroke: A pooled analysis of the SWIFT and STAR studies. JAMA Neurol. 2017, 74, 268-274. [CrossRef]

12. 12. Abilleira, S.; Ribera, A.; Cardona, P.; Rubiera, M.; López-Cancio, E.; Amaro, S.; Rodríguez-Campello, A.; Camps-Renom, P.; Cánovas, D.; De Miquel, M.A.; et al. Outcomes after direct thrombectomy or combined intravenous and endovascular treatment are not different. Stroke 2017, 48, 375-378. [CrossRef] [PubMed]

13. Fischer, U.; Kaesmacher, J.; Pereira, V.M.; Chapot, R.; Siddiqui, A.H.; Froehler, M.T.; Cognard, C.; Furlan, A.J.; Saver, J.L.; Gralla, J. Direct mechanical thrombectomy versus combined intravenous and mechanical thrombectomy in large-artery anterior circulation stroke: A topical review. Stroke 2017, 48, 2912-2918. [CrossRef] [PubMed]

14. Bellwald, S.; Weber, R.; Dobrocky, T.; Nordmeyer, H.; Jung, S.; Hadisurya, J.; Mordasini, P.; Mono, M.L.; Stracke, C.P.; Sarikaya, H.; et al. Direct mechanical intervention versus bridging therapy in stroke patients eligible for intravenous thrombolysis: A pooled analysis of 2 registries. Stroke 2017, 48, 3282-3288. [CrossRef] [PubMed]

15. Rai, A.T.; Boo, S.; Buseman, C.; Adcock, A.K.; Tarabishy, A.R.; Miller, M.M.; Roberts, T.D.; Domico, J.R.; Carpenter, J.S. Intravenous thrombolysis before endovascular therapy for large vessel strokes can lead to significantly higher hospital costs without improving outcomes. J. Neurointerv. Surg. 2018, 10, 17-21. [CrossRef]

16. Malhotra, A.; Wu, X.; Payabvash, S.; Matouk, C.C.; Forman, H.P.; Gandhi, D.; Sanelli, P.; Schindler, J. Comparative effectiveness of endovascular thrombectomy in elderly stroke patients. Stroke 2019, 50,963-969. [CrossRef] 
17. Chandra, R.V.; Leslie-Mazwi, T.M.; Oh, D.C.; Chaudhry, Z.A.; Mehta, B.P.; Rost, N.S.; Rabinov, J.D.; Hirsch, J.A.; González, R.G.; Schwamm, L.H.; et al. Elderly patients are at higher risk for poor outcomes after intra-arterial therapy. Stroke 2012, 43, $2356-2361$. [CrossRef]

18. Goyal, M.; Menon, B.K.; Van Zwam, W.H.; Dippel, D.W.; Mitchell, P.J.; Demchuk, A.M.; Dávalos, A.; Majoie, C.B.; Van der Lugt, A.; De Miquel, M.A.; et al. Endovascular thrombectomy after large-vessel ischaemic stroke: A-meta-analysis of individual patient data from five randomised trials. Lancet 2016, 387, 1723-1731. [CrossRef]

19. Mueller-Kronast, B.K.; Zaidat, O.O.; Froehler, M.T.; Jahan, R.; Aziz-Sultan, M.A.; Klucznik, R.P.; Saver, J.L.; Hellinger, F.R.; Yavagal, D.R.; Yao, T.L.; et al. Systematic evaluation of patients treated with neurothrombectomy devices for acute ischemic stroke: Primary results of the STRATIS registry. Stroke 2017, 48, 2760-2768. [CrossRef]

20. Binning, M.J.; Bartolini, B.; Baxter, B.; Budzik, R.; English, J.; Gupta, R.; Hedayat, H.; Krajina, A.; Liebeskind, D.; Nogueira, R.G.; et al. Trevo 2000: Results of a large real-world registry for stent retriever for acute ischemic stroke. J. Am. Heart Assoc. 2018, 7, e010867. [CrossRef]

21. Alawieh, A.; Chatterjee, A.; Feng, W.; Porto, G.; Vargas, J.; Kellogg, R.; Turk, A.S.; Turner, R.D.; Chaudry, M.I.; Spiotta, A.M. Thrombectomy for acute ischemic stroke in the elderly: A 'real world' experience. J. Neurointerv. Surg. 2018, 10, 1209-1217. [CrossRef]

22. Sharobeam, A.; Cordato, D.J.; Manning, N.; Cheung, A.; Wenderoth, J.; Cappelen-Smith, C. Functional outcomes at 90 days in octogerians undergoing thrombectomy for acute ischemic stroke: A prospective cohort study and meta-analysis. Front. Neurol. 2019, 10, 254. [CrossRef]

23. Wollenweber, F.A.; Tiedt, S.; Alegiani, A.; Alber, B.; Bangard, C.; Berrouschot, J.; Bode, F.J.; Boeckh-Behrens, T.; Bohner, G.; Bormann, A.; et al. Functional outcome following stroke thrombectomy in clinical practice. Stroke 2019, 50, 2500-2506. [CrossRef] [PubMed]

24. Martini, M.; Mocco, J.; Turk, A.; Siddiqui, A.H.; Fiorella, D.; Hanel, R.; Woodward, K.; Rai, A.; Frei, D.; Almandoz, J.E.D.; et al. An international multicenter retrospective study to survey the landscape of thrombectomy in the treatment of anterior circulaton acute ischemic stroke: Outcomes with respect to age. J. Neurointerv. Surg. 2020, 12, 115-121. [CrossRef]

25. Adams, H.P.; Del Zoppo, G.; Alberts, M.J.; Bhatt, D.L.; Brass, L.; Furlan, A.; Grubb, R.L.; Higashida, R.T.; Jauch, E.C.; Kidwell, C.; et al. Guidelines for the early management of adults with ischemic stroke: A guideline from the American Heart Association/American Stroke Association Stroke Council, Clinical Cardiology Council, Cardiovascular Radiology and Intervention Council, and the Atherosclerotic Peripheral Vascular Disease and Quality of Care Outcomes in Research Interdisciplinary Working Groups: The American Academy of Neurology affirms the value of this guideline as an educational tool for neurologists. Stroke 2007, 38, 1655-1711. [CrossRef]

26. Jauch, E.C.; Saver, J.L.; Adams, H.P.; Bruno, A.; Connors, J.J.; Demaerschalk, B.M.; Khatri, P.; McMullan, P.W.; Qureshi, A.I.; Rosenfield, K.; et al. Guidelines for the early management of patients with acute ischemic stroke: A guideline for healthcare professionals from the American Heart Association/American Stroke Association. Stroke 2013, 44, 870-947. [CrossRef]

27. Šaňák, D.; Neumann, J.; Tomek, A.; Školoudík, D.; Škoda, O.; Mikulík, R.; Herzig, R.; Václavík, D.; Bar, M.; Roček, M.; et al. Doporučení pro rekanalizační léčbu akutního mozkového infarktu-Verze 2016. Cesk. Slov. Neurol. N. 2016, 79/112, $231-234$. [CrossRef]

28. Wahlgren, N.; Moreira, T.; Michel, P.; Steiner, T.; Jansen, O.; Cognard, C.; Mattle, H.P.; Van Zwam, W.; Holmin, S.; Tatlisumak, T.; et al. Mechanical thrombectomy in acute ischemic stroke: Consensus statement by ESO-Karolinska Stroke Update 2014/2015, supported by ESO, ESMINT, ESNR and EAN. Int. J. Stroke 2016, 11, 134-147. [CrossRef] [PubMed]

29. Campbell, B.C.; Christensen, S.; Levi, C.R.; Desmond, P.M.; Donnan, G.A.; Davis, S.M.; Parsons, M.W. Cerebral blood flow is the optimal CT perfusion parameter for assessing infarct core. Stroke 2011, 42, 3435-3440. [CrossRef] [PubMed]

30. Neumann, J.; Tomek, A.; Školoudík, D.; Škoda, O.; Mikulík, R.; Herzig, R.; Václavík, D.; Bar, M.; Šaňák, D. Doporučený postup pro intravenózní trombolýzu v léčbě akutního mozkového infarktu—Verze 2014. Cesk. Slov. Neurol. N. 2014, 77/110, 381-385.

31. Šaňák, D.; Nosál, V.; Horák, D.; Bártková, A.; Zeleňák, K.; Herzig, R.; Bučil, J.; Školoudík, D.; Buřval, S.; Cisariková, V.; et al. Impact of diffusion-weighted MRI-measured initial cerebral infarction volume on clinical outcome in acute stroke patients with middle cerebral artery occlusion treated by thrombolysis. Neuroradiology 2006, 48, 632-639. [CrossRef]

32. Van Swieten, J.C.; Koudstaal, P.J.; Visser, M.C.; Schouten, H.J.; Van Gijn, J. Interobserver agreement for the assessment of handicap in stroke patients. Stroke 1988, 19, 604-607. [CrossRef] [PubMed]

33. Goldstein, L.B.; Samsa, G.P. Reliability of the National Institute of Health Stroke Scale. Extension to non-neurologists in the context of a clinical trial. Stroke 1997, 28, 307-310. [CrossRef]

34. Marek, M.; Horyniecki, M.; Fraczek, M.; Kluczewska, E. Leukoaraiosis-New concepts and modern imaging. Pol. J. Radiol. 2018, 83, e76-e81. [CrossRef]

35. Yoo, A.J.; Simonsen, C.Z.; Prabhakaran, S.; Chaudhry, Z.A.; Issa, M.A.; Fugate, J.E.; Linfante, I.; Liebeskind, D.S.; Khatri, P.; Jovin, T.G.; et al. Refining angiographic biomarkers of revascularization: Improving outcome prediction after intra-arterial therapy. Stroke 2013, 44, 2509-2512. [CrossRef]

36. Wahlgren, N.; Ahmed, N.; Dávalos, A.; Ford, G.A.; Grond, M.; Hacke, W.; Hennerici, M.G.; Kaste, M.; Kuelkens, S.; Larrue, V.; et al. Thrombolysis with alteplase for acute ischaemic stroke in the Safe Implementation of Thrombolysis in Stroke-Monitoring Study (SITS-MOST): An observational study. Lancet 2007, 369, 275-282. [CrossRef] 
37. Marini, C.; Baldassarre, M.; Russo, T.; De Santis, F.; Sacco, S.; Ciancarelli, I.; Carolei, A. Burden of first-ever ischemic stroke in the oldest old: Evidence from a population-based study. Neurology 2004, 62, 77-81. [CrossRef] [PubMed]

38. Russo, T.; Felzani, G.; Marini, C. Stroke in the very old: A systematic review of studies on incidence, outcome, and resource use. J. Aging Res. 2011, 2011, 108785. [CrossRef] [PubMed]

39. Kleine, J.F.; Boeckh-Behrens, T.; Prothmann, S.; Zimmer, C.; Liebig, T. Discrepancy between early neurological course and mid-term outcome in older stroke patients after mechanical thrombectomy. J. Neurointerv. Surg. 2016, 8, 671-676. [CrossRef]

40. Arsava, E.M.; Rahman, R.; Rosand, J.; Lu, J.; Smith, E.E.; Rost, N.S.; Singhal, A.B.; Lev, M.H.; Furie, K.L.; Koroshetz, W.J.; et al. Severity of leukoaraiosis correlates with clinical outcome after ischemic stroke. Neurology 2009, 72, 1403-1410. [CrossRef]

41. Henninger, H.; Lin, E.; Baker, S.P.; Wakhloo, A.K.; Takhtani, D.; Moonis, M. Leukoaraiosis predicts poor 90-day outcome after acute large cerebral artery occlusion. Cerebrovasc. Dis. 2012, 33, 525-531. [CrossRef] [PubMed]

42. Ribo, M.; Flores, A.; Mansilla, E.; Rubiera, M.; Tomasello, A.; Coscojuela, P.; Pagola, J.; Rodriguez-Luna, D.; Muchada, M.; Alvarez-Sabín, J.; et al. Age-adjusted infarct volume threshold for good outcome after endovascular treatment. J. Neurointerv. Surg. 2014, 6, 418-422. [CrossRef]

43. Lima, A.; Haussen, D.C.; Rebello, L.C.; Dehkharghani, S.; Grossberg, J.; Grigoryan, M.; Frankel, M.; Nogueira, R.G. Endovascular therapy for large vessel stroke in the elderly: Hope in the new stroke era. Cerebrovasc. Dis. 2016, 42, 421-427. [CrossRef]

44. Yang, P.; Zhang, Y.; Zhang, L.; Zhang, Y.; Treurniet, K.M..; Chen, W.; Peng, Y.; Han, H.; Wang, J.; Wang, S.; et al. Endovascular thrombectomy with or without intravenous alteplase in acute stroke. J. Clin. Med. 2020, 382, 1981-1993. [CrossRef]

45. Zi, W.; Qiu, Z.; Li, F.; Sang, H.; Wu, D.; Luo, W.; Liu, S.; Yuan, J.; Song, J.; Shi, Z.; et al. Effect of endovascular treatment alone vs. intravenous alteplase plus endovascular treatment on functional independence in patients with acute ischemic stroke. The DEVT randomised clinical trial. JAMA 2021, 325, 234-243. [CrossRef] [PubMed]

46. Suzuki, K.; Matsumaru, Y.; Takeuchi, M.; Morimoto, M.; Kanazawa, R.; Takayama, Y.; Kamila, Y.; Shigeta, K.; Okubo, S.; Haykawa, M.; et al. Effect of mechanical thrombectomy without vs. with intravenous thrombolysis on functional outcome among patients with acute ischemic stroke. The SKIP randomised clinical trial. JAMA 2021, 325, 244-253. [CrossRef] [PubMed]

47. Minnerup, J.; Wersching, H.; Teuber, A.; Wellmann, J.; Eyding, J.; Weber, R.; Reimann, G.; Weber, W.; Krause, L.U.; Kurth, T.; et al. Outcome after thrombectomy and intravenous thrombolysis in patients with acute ischemic stroke: A prospective observational study. Stroke 2016, 47, 1584-1592. [CrossRef]

48. Chalos, V.; LeCouffe, N.E.; Uyttenboogaart, M.; Lingsma, H.F.; Mulder, M.J.H.L.; Venema, E.; Treurniet, K.M.; Eshghi, O.; Van der Worp, H.B.; Van der Lugt, A.; et al. Endovascular treatment with or without prior intravenous alteplase for acute ischemic stroke. J. Am. Heart Assoc. 2019, 8, e011592. [CrossRef] [PubMed]

49. Ahmed, N.; Mazya, M.; Nunes, A.P.; Moreira, T.; Ollikainen, J.P.; Escudero-Martinez, I.; Bigliardi, G.; Dorado, L.; Dávalos, A.; Egido, J.A.; et al. Safety and outcomes of thrombectomy in ischemic stroke with vs. without intravenous thrombolysis. Neurology 2021, 97, e765-e776. [CrossRef]

50. Hacke, W.; Kaste, M.; Fieschi, C.; Von Kummer, R.; Davalos, A.; Meier, D.; Larrue, V.; Bluhmki, E.; Davis, S.; Donnan, G.; et al. Randomised double-blind placebo-controlled trial of thrombolytic therapy with intravenous alteplase in acute ischaemic stroke (ECASS II). Lancet 1998, 352, 1245-1251. [CrossRef]

51. Kidwell, C.S.; Latour, L.; Saver, J.L.; Alger, J.R.; Starkman, S.; Duckwiler, G.; Jahan, R.; Vinuela, F.; Kang, D.W.; Warach, S. Thrombolytic toxicity: Blood brain barrier disruption in human ischemic stroke. Cerebrovasc. Dis. 2008, 25, 338-343. [CrossRef] [PubMed]

52. Strbian, D.; Engelter, S.; Michel, P.; Meretoja, A.; Sekoranja, L.; Ahlhelm, F.J.; Mustanoja, S.; Kuzmanovic, I.; Sairanen, T.; Forss, N.; et al. Symptomatic intracranial hemorrhage after stroke thrombolysis: The SEDAN score. Ann. Neurol. 2012, 71, 634-641. [CrossRef] [PubMed]

53. Chalos, V.; De Ridder, I.R.; Lingsma, H.F.; Brown, S.; Van Oostenbrugge, R.J.; Goyal, M.; Campbell, B.C.V.; Muir, K.W.; Guillemin, F.; Bracard, S.; et al. Does sex modify the effect of endovascular treatment for ischemic stroke? Stroke 2019, 50, 2413-2419. [CrossRef]

54. Sheth, S.A.; Lee, S.; Warach, S.J.; Gralla, J.; Jahan, R.; Goayl, M.; Nogueira, R.G.; Zaidat, O.O.; Pereira, V.M.; Siddiqui, A.; et al. Sex differences in outcome after endovascular stroke therapy for acute ischemic stroke. Stroke 2019, 50, 2420-2427. [CrossRef]

55. Uchida, K.; Yoshimura, S.; Sakai, N.; Yamagami, H.; Morimoto, T. Sex differences in management and outcomes of acute ischemic stroke with large vessel occlusion. Stroke 2019, 50, 1915-1918. [CrossRef]

56. Madsen, T.E.; DeCroce-Movson, E.; Hemendinger, M.; McTaggart, R.A.; Yaghi, S.; Cutting, S.; Furie, K.L.; Saad, A.; Siket, M.S.; Jayaraman, M.V. Sex differences in 90-day outcomes after mechanical thrombectomy for acute ischemic stroke. J. Neurointerv. Surg. 2019, 11, 221-225. [CrossRef] [PubMed] 